\title{
PERAMALAN KUNJUNGAN WISATAWAN MANCANEGARA KE PROVINSI BALI MENGGUNAKAN METODE ARTIFICIAL NEURAL NETWORK
}

\author{
I Ketut Restu Wiranata $^{1 \S}$, G.K. Gandhiadi ${ }^{2}$, Luh Putu Ida Harini ${ }^{3}$ \\ ${ }^{1}$ Program Studi Matematika, Fakultas MIPA - Universitas Udayana [Email: restuwiranata98@gmail.com] \\ ${ }^{2}$ Program Studi Matematika, Fakultas MIPA - Universitas Udayana [Email: gandhiadi@unud.ac.id] \\ ${ }^{3}$ Program Studi Matematika, Fakultas MIPA - Universitas Udayana [Email: ballidah@unud.ac.id] \\ ${ }^{\S}$ Corresponding Author
}

\begin{abstract}
Bali has an increasing tourism potential. This is evidenced by the increasing number of foreign tourist visits to Bali Province each year. Although Bali's tourism trends have continued to increase over the past few years, efforts to improve the quality of Bali tourism need to be made. One way is to do forecasting. To support improvement efforts in Bali's tourism sector, the author created a forecasting system for foreign tourists to Bali province using artificial neural network methods with back propagation algorithms. Artificial Neural Networks with back propagation algorithms are neural network algorithms by finding optimal weight values. The forecast results using the binary sigmoid activation function were obtained by 489,862 foreign tourists in November 2019 with MAPE at $1.62 \%$ and 487,342 foreign tourists in December 2019 with MAPE of 11.78\%. The forecast results using the bipolar sigmoid activation function were obtained by 493,200 foreign tourists in November 2019 with MAPE of 0.95\% and 484,090 foreign tourists in December 2019 with MAPE of $12.37 \%$.
\end{abstract}

Keywords: Artificial neural network, foreign tourists visit, forecasting

\section{PENDAHULUAN}

Berdasarkan data United Nations World Tourism Organization (UNWTO) mencatat pendapatan ekspor yang dihasilkan oleh pariwisata telah tumbuh menjadi US\$ 1,7 triliun secara global. Hal ini membuat sektor pariwisata menjadi salah satu kekuatan pertumbuhan ekonomi dan mendorong terciptanya lapangan pekerjaan yang lebih baik di dunia (UNWTO, 2019).

Indonesia merupakan salah satu negara berkembang yang memiliki peningkatan angka jumlah kunjungan wisatawan mancanegara (wisman) setiap tahunnya. Badan Pusat Statistik Provinsi Bali (2019) mencatat jumlah kunjungan wisman periode Januari-September 2019 ke Indonesia mencapai 12,27 juta kunjungan atau naik 2,63 persen dibandingkan dengan jumlah kunjungan wisman pada periode yang sama pada tahun 2018 yang berjumlah 11,96 juta kunjungan. Kedatangan wisman ke Provinsi Bali September 2019 tercatat sebanyak 590.565 orang. Bila dibandingkan dengan bulan September 2018, jumlah wisman ke Bali tercatat mengalami kenaikan setinggi 6,24 persen pada September 2019. Meskipun tren pariwisata Bali terus meningkat selama beberapa tahun terakhir, akan tetapi upaya peningkatan kualitas pariwisata Bali perlu dilakukan. Peningkatan kualitas ini dapat dilakukan jika data kunjungan wisman pada tahun berikutnya telah diketahui. Salah satu caranya dengan melakukan peramalan.

Peramalan adalah kegiatan mengestimasi apa yang akan terjadi pada masa yang akan datang dengan mempertimbangkan kejadian masa lampau dan pengaruh kondisi saat ini (Murahartawaty, 2009). Seiring dengan perkembangan ilmu di bidang komputasi, berbagai metode telah diimplementasikan dalam melakukan peramalan seperti Fuzzy, ANFIS, Artificial Neural Network (ANN), dan lain-lain. Fausett (1994) mendefinisikan artificial neural network sebagai sistem pemrosesan informasi yang memiliki karakter kinerja tertentu yang sama dengan jaringan saraf manusia. Salah satu algoritme $A N N$ yang 
memiliki akurasi baik adalah backpropagation. Backpropagation merupakan algoritme pembelajaran yang terawasi untuk mencari nilai bobot optimal. Backpropagation neural network memiliki kelebihan karena pembelajarannya dilakukan berulang-ulang sehingga dapat mengerjakan sistem yang tahan akan kerusakan dan konsisten bekerja dengan baik (Anwar, 2011).

Hingga saat ini pengembangan terhadap $A N N$ terus dilakukan baik dalam meningkatkan akurasi maupun mempercepat proses pembelajaran ANN itu sendiri. Seperti penelitian yang dilakukan Claveria \& Torra (2015) yang bertujuan untuk membandingkan kinerja ANN dengan tiga algoritme berbeda untuk peramalan data wisatawan. Selanjutnya, penelitian yang dilakukan Sawitri, dkk. (2018) melakukan peramalan menggunakan metode backpropagation neural network untuk mengukur hasil peramalan harga beras di Kota Denpasar pada tahun 2017.

Adapun tujuan dari penelitian ini adalah mendapat model arsitektur ANN dengan menggunakan data set yang tersedia untuk peramalan kunjungan wisatawan mancanegara ke Provinsi Bali dan meramalkan kunjungan wisatawan mancanegara ke Provinsi Bali dengan menggunakan model arsitektur yang didapat.

\section{METODE PENELITIAN}

\section{Jenis dan Sumber Data}

Jenis data yang digunakan dalam penelitian ini adalah data sekunder. Data tersebut merupakan jumlah kedatangan wisatawan mancanegara ke Provinsi Bali periode Januari 2009 sampai Oktober 2018 yang diperoleh dari Badan Pusat Statistik Provinsi Bali.

\section{Metode Analisis Data}

Metode pengolahan data yang dilakukan dalam penelitian ini yaitu menggunakan metode artificial neural networks dengan algoritme pelatihan backpropagation. Algoritme pelatihan backpropagation akan dikerjakan menggunakan software ANACONDA. Pemilihan model arsitektur dilakukan dengan cara mencari kombinasi arsitektur terbaik antara input, jumlah lapisan tersembunyi, dan output.

Langkah-langkah pengolahan data dalam metode artificial neural networks dengan algoritme pelatihan backpropagation adalah sebagai berikut :

1 Melakukan normalisasi data dengan minmax normalization method:

$f(v)=\frac{v-\min (v)}{\max (v)-\min (v)}$

dengan $f(v)$ menyatakan nilai data yang telah dinormalisasi, $v$ menyatakan nilai data sebelum dinormalisasi, $\min (v)$ menyatakan nilai minimum dari seluruh data, $\max (v)$ menyatakan nilai maksimum dari seluruh data.

2 Menentukan nilai input dan target (output) dalam bentuk matriks menggunakan transformasi data time series. (Bulan ke- $\mathrm{i}$ sampai bulan ke-i+11 sebagai nilai input dan nilai target (output) menggunakan data kunjungan wisman bulan ke-i+12)

3 Membagi data menjadi dua bagian, yaitu data untuk pelatihan dan data pengujian. ((1)70\% data latih dengan 30\% data uji, (2) $75 \%$ data latih dengan $25 \%$ data uji, dan (3) $80 \%$ data latih dengan $20 \%$ data uji)

4 Menentukan banyak unit neuron pada lapisan tersembunyi.

5 Menentukan fungsi aktivasi.

Fungsi aktivasi yang digunakan pada lapisan tersembunyi dan lapisan output yaitu : fungsi aktivasi sigmoid biner dan sigmoid bipolar.

6 Inisialisasi bobot secara random.

7 Menetapkan maksimum iterasi. (Iterasi yang digunakan sebanyak 1.000 iterasi)

8 Melakukan proses backpropagation neural network terhadap data pelatihan dan data pengujian.

9 Memilih model arsitektur dengan nilai MSE terkecil pada data pelatihan.

10 Dilanjutkan ke data pengujian menggunakan MSE terkecil pada data pelatihan dan selanjutnya dilihat MSE pada data pengujian.

11 Melakukan regularisasi terhadap data pelatihan dan data pengujian. (Pada tahap ini overfitting pada ANN diminimalkan)

12 Melihat MSE data pelatihan dan data pengujian setelah diregularisasi.

13 Menggunakan model arsitektur dengan nilai MSE terkecil untuk meramalkan jumlah kedatangan wisatawan mancanegara ke Provinsi Bali.

14 Hasil prediksi jumlah kedatangan wisatawan mancanegara ke Provinsi Bali pada November dan Desember tahun 2019 
dinormalisasi kembali dengan min-max normalization method.

15 Interpretasi hasil.

\section{HASIL DAN PEMBAHASAN}

\subsection{Tahap Pelatihan}

Tahap pelatihan jaringan merupakan proses pembelajaran terhadap pola yang akan dikenali. Pada penelitian ini tahap pelatihan arsitektur artificial neural network akan menggunakan data pelatihan dengan proporsi, yaitu: (1) proporsi dengan $70 \%$ data pelatihan (83 data), (2) proporsi dengan $75 \%$ data pelatihan $(88$ data), dan (3) proporsi dengan $80 \%$ data pelatihan (94 data). Tahap pelatihan jaringan akan dilakukan sebanyak dua kali untuk masing-masing fungsi aktivasi, yaitu dengan fungsi aktivasi sigmoid biner sebanyak dua kali percobaan dan fungsi aktivasi sigmoid bipolar sebanyak dua kali percobaan. Tahap pelatihan jaringan dilakukan dengan mencoba neuron pada lapisan tersembunyi pada rentang 1 hingga 9 neuron. Tabel berikut memperlihatkan arsitektur jaringan yang dicoba pada tahap pelatihan.

Tabel 1. Tahap Pelatihan Arsitektur $12-n-1$ dengan Fungsi Aktivasi Sigmoid Biner

\begin{tabular}{|c|c|c|c|}
\hline $\begin{array}{c}\text { Arsitektur } \\
\text { Jaringan }\end{array}$ & $\begin{array}{c}\text { Rata-rata } \\
\text { MSE 70\% }\end{array}$ & $\begin{array}{c}\text { Rata-rata } \\
\text { MSE 75\% }\end{array}$ & $\begin{array}{c}\text { Rata-rata } \\
\text { MSE 80\% }\end{array}$ \\
\hline $12-1-1$ & 0,1057748 & 0,108287 & 0,097899 \\
\hline $12-2-1$ & 0,0455902 & 0,0424711 & 0,052074 \\
\hline $12-3-1$ & 0,0321803 & 0,02831 & 0,022526 \\
\hline $12-4-1$ & 0,0214840 & 0,022363 & 0,03125 \\
\hline $12-5-1$ & 0,0192258 & 0,020918 & 0,020247 \\
\hline $12-6-1$ & 0,0194451 & 0,021211 & 0,020321 \\
\hline $\mathbf{1 2}-\mathbf{7}-\mathbf{1}$ & $\mathbf{0 , 0 1 4 9 8 9 5}$ & 0,017231 & 0,018133 \\
\hline $12-8-1$ & 0,016945 & 0,01663 & 0,019955 \\
\hline $12-9-1$ & 0,017857 & 0,02066 & 0,020054 \\
\hline
\end{tabular}

Sumber: Data diolah (2020)

Pada Tabel 1 terlihat bahwa penambahan jumlah neuron pada lapisan tersembunyi belum tentu menyebabkan penurunan nilai $M S E$ akhir. Nilai $M S E$ akhir terkecil didapat oleh arsitektur yang menggunakan 7 neuron pada lapisan tersembunyi dengan proporsi data 70\% (83 data) yaitu sebesar 0,0149895.

Pada Tabel 2 terlihat bahwa penambahan jumlah neuron pada lapisan tersembunyi belum tentu menyebabkan penurunan nilai $M S E$ akhir. Nilai MSE akhir terkecil didapat oleh arsitektur yang menggunakan 8 neuron pada lapisan tersembunyi dengan proporsi data $70 \%$ (83 data) yaitu sebesar 0,0139999.
Tabel 2. Tahap Pelatihan Arsitektur $12-n-1$ dengan Fungsi Aktivasi Sigmoid Bipolar

\begin{tabular}{|c|c|c|c|}
\hline $\begin{array}{c}\text { Arsitektur } \\
\text { Jaringan }\end{array}$ & $\begin{array}{c}\text { Rata-rata } \\
\text { MSE 70\% }\end{array}$ & $\begin{array}{c}\text { Rata-rata } \\
\text { MSE 75\% }\end{array}$ & $\begin{array}{c}\text { Rata-rata } \\
\text { MSE 80\% }\end{array}$ \\
\hline $12-1-1$ & 0,0970643 & 0,096104 & 0,0849076 \\
\hline $12-2-1$ & 0,0347588 & 0,020831 & 0,033636 \\
\hline $12-3-1$ & 0,0204415 & 0,034095 & 0,02184 \\
\hline $12-4-1$ & 0,0208294 & 0,0213557 & 0,0197705 \\
\hline $12-5-1$ & 0,019317 & 0,022968 & 0,0214785 \\
\hline $12-6-1$ & 0,0163545 & 0,016307 & 0,023528 \\
\hline $12-7-1$ & 0,0148165 & 0,01621 & 0,0175715 \\
\hline $\mathbf{1 2}-\mathbf{8}-\mathbf{1}$ & $\mathbf{0 , 0 1 3 9 9 9 9}$ & 0,017365 & 0,0188057 \\
\hline $12-9-1$ & 0,0192106 & 0,0168925 & 0,0181592 \\
\hline
\end{tabular}

Sumber: Data diolah (2020)

\subsection{Tahap Pengujian}

Tahap pengujian jaringan digunakan untuk menguji jaringan yang telah dilatihkan dengan memasukkan data baru yang belum pernah dilatih sebelumnya untuk mengetahui nilai akurasi yang dihasilkan. Pada tahap ini arsitektur artificial neural network akan menggunakan data pengujian dengan proporsi $30 \%$ (35 data). Arsitektur yang dipakai pada tahap pengujian adalah jaringan yang menghasilkan nilai MSE terkecil saat pelatihan. Tabel berikut menunjukkan nilai MSE arsitektur pelatihan dengan data pengujian.

Tabel 3. Nilai MSE Arsitektur Pelatihan dengan Data Pengujian

\begin{tabular}{|c|c|c|}
\hline $\begin{array}{c}\text { Arsitektur } \\
\text { Jaringan }\end{array}$ & Fungsi Aktivasi & MSE \\
\hline $12-7-1$ & Sigmoid biner & 1,8207627 \\
\hline $12-8-1$ & Sigmoid bipolar & 3,1720104 \\
\hline
\end{tabular}

Sumber: Data diolah (2020)

\subsection{Hasil Pelatihan dan Pengujian Jaringan}

Hasil pelatihan dan pengujian arsitektur jaringan yang digunakan pada penelitian ini menggunakan arsitektur jaringan yang menghasilkan nilai MSE terkecil, yaitu: arsitektur jaringan 12-7-1 dengan fungsi aktivasi sigmoid biner dan arsitektur jaringan 12-8-1 dengan fungsi aktivasi sigmoid bipolar. Tabel berikut menunjukkan nilai MSE hasil pelatihan dan pengujian arsitektur jaringan.

Berdasarkan Tabel 4 terlihat bahwa nilai MSE pelatihan terkecil dengan fungsi aktivasi sigmoid biner dihasillkan oleh arsitektur jaringan 12-7-1 yaitu sebesar 0,0149895 dan pada tahap pengujian nilai MSE yang dihasilkan sebesar 1,8207627 serta nilai MSE 
pelatihan terkecil dengan fungsi aktivasi sigmoid bipolar dihasillkan oleh arsitektur jaringan 12-8-1 yaitu sebesar 0,0139999 dan pada tahap pengujian nilai MSE yang dihasilkan sebesar 3,1720104.

Tabel 4. Hasil Pelatihan dan Pengujian Jaringan

\begin{tabular}{|c|l|l|l|}
\hline $\begin{array}{l}\text { Arsitektur } \\
\text { jaringan }\end{array}$ & $\begin{array}{l}\text { Fungsi } \\
\text { aktivasi }\end{array}$ & Pelatihan & Pengujian \\
\cline { 3 - 4 } & MSE & MSE \\
\hline $12-7-1$ & $\begin{array}{l}\text { Sigmoid } \\
\text { Biner }\end{array}$ & 0,0149895 & 1,8207627 \\
\hline $12-8-1$ & $\begin{array}{l}\text { Sigmoid } \\
\text { Bipolar }\end{array}$ & 0,0139999 & 3,1720104 \\
\hline
\end{tabular}

Sumber: Data diolah (2020)

Gambar berikut menunjukkan nilai MSE pada pelatihan (garis biru) dan pengujian (garis oranye).

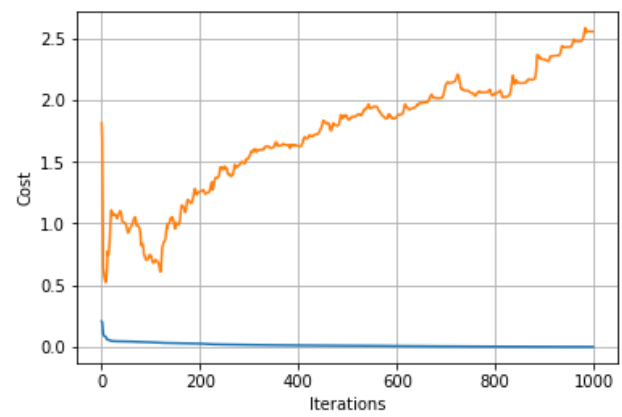

Gambar 1. Hasil MSE Pelatihan dan Pengujian dengan Fungsi Aktivasi Sigmoid Biner

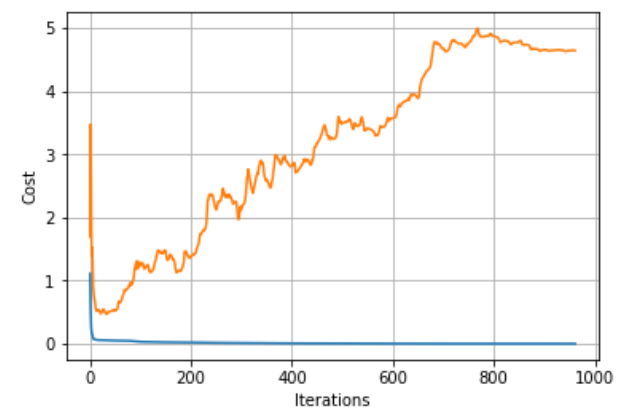

Gambar 2. Hasil MSE Pelatihan dan Pengujian dengan Fungsi Aktivasi Sigmoid Bipolar

Dapat dilihat pada Gambar 1 dan 2 hasil MSE dari data pelatihan cenderung menurun dan MSE dari data pengujian cenderung meningkat. Terlihat bahwa model ANN yang dibentuk dapat menyebabkan overfitting, maka untuk mengurangi kemungkinan terjadinya overfitting akan dilakukan metode regularisasi.

\subsection{Regularisasi pada Tahapan Pelatihan dan Pengujian}

Regularisasi pada dasarnya menambah penalti sewaktu kompleksitas model meningkat. Parameter regularisasi (lambda) menyingkirkan semua parameter kecuali intersep sehingga model digeneralisasi dan tidak terjadi overfitting (Nagpal, 2017). Parameter regularisasi (lambda) yang digunakan pada penelitian ini bernilai 0,0001. Tabel berikut menunjukkan nilai MSE pelatihan dan pengujian arsitektur dengan fungsi aktivasi sigmoid biner dan sigmoid bipolar yang telah diregularisasi.

Tabel 5. Hasil Pelatihan dan Pengujian Jaringan Setelah Diregularisasi

\begin{tabular}{|l|l|l|l|}
\hline Arsitektur & \multirow{2}{*}{$\begin{array}{l}\text { Fungsi } \\
\text { aktivasi }\end{array}$} & \multicolumn{2}{|c|}{ MSE } \\
\cline { 3 - 4 } & & Pelatihan & Pengujian \\
\hline $12-7-1$ & $\begin{array}{l}\text { Sigmoid } \\
\text { Biner }\end{array}$ & 0,0068981 & 0,009289 \\
\hline $12-8-1$ & $\begin{array}{l}\text { Sigmoid } \\
\text { Bipolar }\end{array}$ & 0,004529 & 0,005721 \\
\hline
\end{tabular}

Sumber: Data diolah (2020)

Berdasarkan Tabel 5 terlihat bahwa nilai MSE pelatihan terkecil dengan fungsi aktivasi sigmoid biner dihasillkan oleh jaringan 12-7-1 sebesar 0,0068981 dan pada tahap pengujian nilai MSE yang dihasilkan sebesar 0,009289 serta nilai MSE pelatihan terkecil dengan fungsi aktivasi sigmoid bipolar dihasillkan oleh jaringan $12-8-1$ sebesar 0,004529 dan pada tahap pengujian nilai MSE yang dihasilkan sebesar 0,005721. Gambar berikut menunjukkan nilai MSE pada pelatihan (garis biru) dan pengujian (garis oranye).

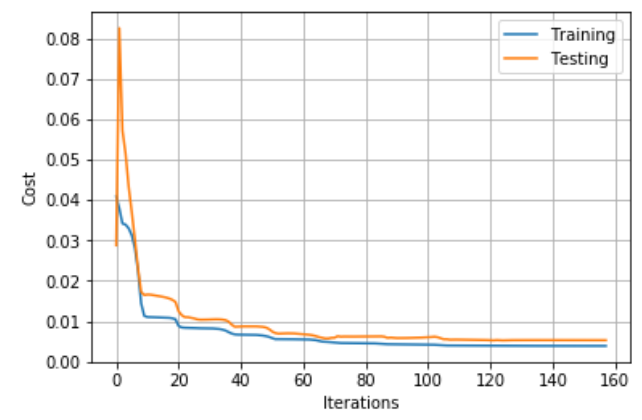

Gambar 3. Hasil MSE Pelatihan dan Pengujian dengan Fungsi Aktivasi Sigmoid Biner Setelah Diregularisasi 


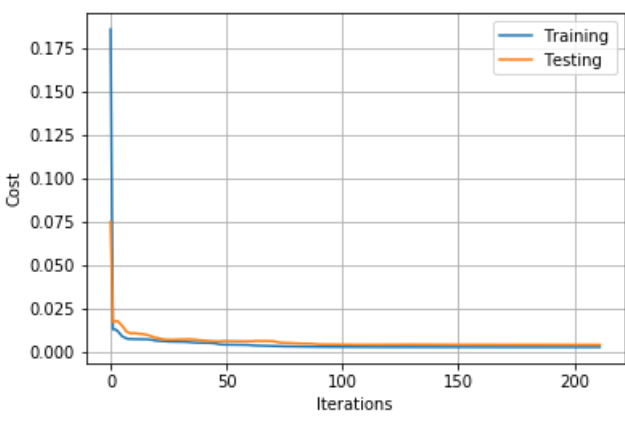

Gambar 4. Hasil MSE Pelatihan dan Pengujian dengan Fungsi Aktivasi Sigmoid Bipolar Setelah Diregularisasi

Terlihat pada Gambar 3 dan 4 hasil MSE dari data pelatihan (garis biru) dan MSE dari data pengujian (garis oranye) cenderung menurun, maka model $A N N$ yang dibentuk cenderung tidak menyebabkan overfitting. Sehingga untuk meramalkan jumlah kedatangan wisatawan mancanegara (wisman) ke Provinsi Bali pada November dan Desember tahun 2019 dipilih arsitektur jaringan, yaitu:

1. Arsitektur jaringan 12-7-1 dengan fungsi aktivasi sigmoid biner yang telah diregularisasi,

2. Arsitektur jaringan 12-8-1 dengan fungsi aktivasi sigmoid bipolar yang telah diregularisasi.

Tabel berikut menunjukkan hasil ramalan yang diperoleh dengan fungsi aktivasi sigmoid biner dan sigmoid bipolar yang telah diregularisasi.

Tabel 6. Hasil Ramalan Artificial Neural Network pada November dan Desember Tahun 2019

\begin{tabular}{|l|l|l|l|}
\hline Bulan & $\begin{array}{l}\text { Arsitektur } \\
\text { jaringan }\end{array}$ & $\begin{array}{l}\text { Fungsi } \\
\text { aktivasi }\end{array}$ & $\begin{array}{l}\text { Hasil } \\
\text { Ramalan }\end{array}$ \\
\hline November & $12-7-1$ & $\begin{array}{l}\text { Sigmoid } \\
\text { Biner }\end{array}$ & 489.862 \\
\cline { 2 - 4 } & $12-8-1$ & $\begin{array}{l}\text { Sigmoid } \\
\text { Bipolar }\end{array}$ & 493.200 \\
\hline Desember & $12-7-1$ & $\begin{array}{l}\text { Sigmoid } \\
\text { Biner }\end{array}$ & 487.342 \\
\cline { 2 - 4 } & $12-8-1$ & $\begin{array}{l}\text { Sigmoid } \\
\text { Bipolar }\end{array}$ & 484.090 \\
\hline
\end{tabular}

Sumber: Data diolah (2020)

Selanjutnya, akan dilihat perbandingan antara hasil ramalan Artificial Neural Network yang telah diperoleh dengan data riil yang diperoleh dari Badan Pusat Statistik Provinsi Bali pada tabel berikut.
Tabel 7. Perbandingan Hasil Ramalan ANN November dan Desember Tahun 2019 dengan Data Riil dari Badan Pusat Statistik Provinsi Bali

\begin{tabular}{|l|l|l|l|l|l|}
\hline Bulan & $\begin{array}{l}\text { Arsitektur } \\
\text { jaringan }\end{array}$ & $\begin{array}{l}\text { Fungsi } \\
\text { aktivasi }\end{array}$ & $\begin{array}{l}\text { Hasil } \\
\text { Ramalan } \\
\text { ANN }\end{array}$ & $\begin{array}{l}\text { Data } \\
\text { Riil }\end{array}$ & MAPE \\
\hline November & $12-7-1$ & $\begin{array}{l}\text { Sigmoid } \\
\text { Biner }\end{array}$ & 489.862 & 497.925 & 0,0162 \\
\cline { 2 - 6 } & $12-8-1$ & $\begin{array}{l}\text { Sigmoid } \\
\text { Bipolar }\end{array}$ & 493.200 & 497.925 & 0,0095 \\
\hline Desember & $12-7-1$ & $\begin{array}{l}\text { Sigmoid } \\
\text { Biner }\end{array}$ & 487.342 & 552.403 & 0,1178 \\
\cline { 2 - 6 } & $12-8-1$ & $\begin{array}{l}\text { Sigmoid } \\
\text { Bipolar }\end{array}$ & 484.090 & 552.403 & 0,1237 \\
\hline
\end{tabular}

Sumber: Data diolah (2020)

Berdasarkan pada Tabel 7 dapat dilihat bahwa seluruh MAPE berada di kisaran 0,95\% - 12,37\% dengan rincian sebagai berikut:

1. MAPE pada November 2019 adalah 0,0162 $(1,62 \%)$ untuk sigmoid biner, dan 0,0095 $(0,95 \%)$ untuk sigmoid bipolar,

2. MAPE pada Desember 2019 adalah 0,1178 $(11,78 \%)$ untuk sigmoid biner, dan 0,1237 $(12,37 \%)$ untuk sigmoid bipolar.

\section{KESIMPULAN DAN SARAN}

\subsection{Kesimpulan}

Berdasarkan hasil dan pembahasan dalam skripsi ini, maka dapat ditarik simpulan sebagai berikut:

1. Berdasarkan hasil pelatihan diperoleh arsitektur artificial neural network dengan fungsi aktivasi sigmoid biner yang memperoleh nilai MSE terkecil adalah arsitektur yang terdiri dari satu neuron input, tujuh neuron tersembunyi, dan satu neuron output. Selanjutnya, dengan fungsi aktivasi sigmoid bipolar nilai MSE terkecil diperoleh arsitektur yang terdiri dari satu neuron input, delapan neuron tersembunyi, dan satu neuron output.

2. Pada penelitian ini diperoleh hasil peramalan jumlah kedatangan wisatawan mancanegara ke Provinsi Bali dengan fungsi aktivasi sigmoid biner sebesar 489.862 wisatawan mancanegara pada November 2019, 487.342 wisatawan mancanegara pada Desember 2019. Selanjutnya, dengan fungsi aktivasi sigmoid bipolar diperoleh sebesar 493.200 wisatawan mancanegara pada November 2019, 484.090 wisatawan mancanegara pada Desember 2019 dengan MAPE berada di kisaran $0,95 \%-12,37 \%$. 


\subsection{Saran}

Arsitektur artificial neural network yang digunakan pada penelitian ini belum sanggup dikatakan menjadi hasil terbaik menilik masih banyak potensi kombinasi yang digunakan, baik itu pola pada input data, banyak neuron pada lapisan tersembunyi, dan jumlah maksimum iterasi. Hal ini dikarenakan pemilihan parameter-parameter tersebut ditentukan dengan cara trial and error. Selain itu, penting adanya penelitian lebih lanjut akan jumlah kedatangan wisatawan mancanegara ke Provinsi Bali dengan menggunakan penambahan variabel lain yang berpotensi memiliki pengaruh terhadap jumlah kedatangan wisatawan mancanegara ke Provinsi Bali sehingga untuk penelitian selanjutnya bisa mencapai peramalan yang lebih akurat.

\section{DAFTAR PUSTAKA}

Anwar, B. (2011). Penerapan algoritme jaringan syaraf tiruan backpropagation dalam memprediksi tingkat suku bunga bank. Jurnal SAINTIKOM, 10(2), 111-123.

Badan Pusat Statistik Provinsi Bali. (2019). Jumlah Wisatawan Asing ke Bali Menurut Bulan, 1982-2020. [Online] Available at: https://bali.bps.go.id/statictable/2018/02/09 /21/jumlah-wisatawan-asing-ke-balimenurut-bulan-1982-2020.html [Accessed 25 November 2019].

Badan Pusat Statistik Provinsi Bali. (2019). Perkembangan Pariwisata Provinsi Bali September 2019. [Online] Available at: https://bali.bps.go.id/pressrelease/2019/11/ 01/717190/perkembangan-pariwisataprovinsi-bali-september-2019--.html [Accessed 25 November 2019].

Claveria, O., \& Torra, S. (2015). Tourism demand forecasting with neural network models : Different ways of treating information. International Journal of Tourism Research, 17(5), 492-500.

Eesa, A. S., \& Arabo, W. (2017). NORMALIZATION METHODS FOR BACKPROPAGATION : A COMPARATIVE STUDY. Science Journal of University of Zakho, 5(4), 319323.
Fausett, L. (1994). Fundamentals of Neural Network (Architectures, Algorithms, and Applications). Upper Sadle River, New Jersey: Prentice-Hall.

Heaton, J. (2008). Introduction to Neural Networks for C\#. (WordsRU.com, Ed.) (Second, Vol. 99). Heaton Research, Inc.

Murahartawaty. 2009. Peramalan. Jakarta: Sekolah Tinggi Teknologi Telkom.

Nagpal, A. (2017). Over-fitting and Regularization. [Online] Available at: https://towardsdatascience.com/overfitting-and-regularization-64d16100f45c [Accessed 2 February 2020].

Sawitri, M. N. D., Sumarjaya, I. W., \& Tastrawati, N. K. T. (2018). PERAMALAN MENGGUNAKAN METODE BACKPROPAGATION. EJurnal Matematika, 7(3), 264-270.

Siang, J. J. (2004). Jaringan Saraf Tiruan dan Pemrogramannya Menggunakan Mathlab. Yogyakarta: Andi Offset.

UNWTO. (2019). International Tourism Highlights 2019 Edition. [Online] Available at: https://www.eunwto.org/doi/book/10,18111/9789284421 152 [Accessed 27 November 2019]. 